\title{
Microsatellite DNA markers and their correlation with growth traits in mandarin fish (Siniperca chuatsi)
}

\author{
L.F. Sun*, J. Li ${ }^{*}$ X.F. Liang, T.L. Yi, L. Fang, J. Sun, Y.H. He, X.N. Luo, \\ Y.Q. Dou and M. Yang \\ Key Lab of Freshwater Animal Breeding, College of Fisheries, \\ Ministry of Agriculture, Huazhong Agricultural University, \\ Freshwater Aquaculture Collaborative Innovation Center of Hubei Province, \\ Wuhan, Hubei, China \\ *These authors contributed equally to this study. \\ Corresponding author: X.F. Liang \\ E-mail: xufang_liang@hotmail.com \\ Genet. Mol. Res. 14 (4): 19128-19135 (2015) \\ Received August 24, 2015 \\ Accepted October 30, 2015 \\ Published December 29, 2015 \\ DOI http://dx.doi.org/10.4238/2015.December.29.22
}

\begin{abstract}
The mandarin fish (Siniperca chuatsi) is a traditionally cultured freshwater fish with high commercial value in China. To facilitate markerassisted selection in genetic improvement of this species, 120 microsatellite markers from the literature were characterized in the 25 largest and 25 smallest individuals. Eighteen polymorphic loci were then used to genotype 200 individuals, and the associations between their genotypes and growth traits were examined. We found that eight genotypes of six loci (AP 37-06, $A P$ 37-11, $A P$ 37-16, AP 37-48, AP 38-32, and AP 39-05) were positively correlated with growth traits (body weight, length, and height) in the mandarin fish population. The average observed and expected heterozygosities were 0.68 and 0.59 , respectively, and the average PIC value was 0.50 , indicating a population with high genetic diversity. Therefore, these markers could be useful for assisted selection in genetic breeding of this species and its related species.
\end{abstract}

Key words: Mandarin fish; Microsatellite; Growth traits; Genetic diversity 


\section{INTRODUCTION}

The mandarin fish, Siniperca chuatsi (Basilewsky), mainly distributed in the Yangtze and Pearl Rivers, is an economically important species in China and has a relatively high market value, and it is widely cultured throughout the country (Liang, 1996; Liu et al., 1998). It has a fast growth rate but is susceptible to diseases and viral infections (Sun and Nie, 2004). Artificial reproduction and selective breeding programs have been undertaken to meet market demand for $S$. chuatsi (Yang et al., 2007; Mi et al., 2010). An assessment of the population genetics of this species is urgently needed to reveal its available germplasm resources as a basis for breeding programs and to determine the potential genetic risk of translocation.

Microsatellites, also known as simple sequence repeats (SSRs), are rapidly developing molecular markers in recent years. Microsatellites are characterized as being highly polymorphic, plenty and well-distributed in the genome (Gpta and Rustgi, 2004). Therefore, they have become a useful tool in population genetics analysis, genetic mapping and marker-assisted selection (MAS) to assess genetic diversity and develop molecular-breeding techniques in fish (Walter and Epperson, 2001; Saha et al., 2004).

The aim of this study was to identify and confirm molecular markers that are associated with growth traits in the mandarin fish. They could provide a valuable theoretical basis for MAS to breed a disease-resistant and faster growing strain and to preserve the fish germplasm.

\section{MATERIAL AND METHODS}

\section{Fish and DNA samples}

A hatchery population was produced by mass spawning of $S$. chuatsi from Qingyuan Yushun Farming \& Fishery Science and Technology Service Co. Ltd. (Qingyuan, Guangdong Province, China) and 200 individuals were randomly sampled half a year post-fertilization. Genomic DNA of these 200 individuals was extracted from the caudal fin using the TIANamp Genomic DNA kit (Tiangen Biotechnology (Beijing) Co. Ltd., China) following the manufacturer directions.

\section{Polymorphic analysis and genotyping}

Library preparation for transcriptome analysis and sequence assembly was as previously described (Wang et al., 2010). This unigene set was used for mining EST-SSR markers using the default parameters of BatchPrimer3 v1.0 software (You et al., 2008). In this study, a subset of 120 SSR markers were collected from the literature (Cnaani et al., 2003) and initially screened in the 25 largest and 25 smallest individuals from 200 samples according to total weight and length for marker association analysis in an isolated population. Subsequently, the initially selected microsatellites were further screened in another 200 individuals for marker association analysis in a randomly selected population (Cnaani et al., 2003). Polymerase chain reaction (PCR) conditions were optimized for each of the primers (Table 1). PCR was performed in $25-\mu \mathrm{L}$ reaction volumes containing $2.5 \mu \mathrm{L}$ 10X PCR buffer, 1.0-3.0 mM MgCl, $50 \mu \mathrm{M}$ dNTPs, $0.4 \mu \mathrm{M}$ each primer, $1 \mathrm{U}$ Taq polymerase (Takara Biotechnology (Dalian) Co. Ltd., China) and 50 ng genomic DNA. PCR conditions were as follows: initial denaturation at $94^{\circ} \mathrm{C}$ for 3 min followed by 35 cycles at $94^{\circ} \mathrm{C}$ for $30 \mathrm{~s}$, the optimized annealing temperature for $30 \mathrm{~s}, 72^{\circ} \mathrm{C}$ for $30 \mathrm{~s}$, and then a final extension 
step at $72^{\circ} \mathrm{C}$ for $10 \mathrm{~min}$. PCR products were separated by $8 \%$ non-denaturing polyacrylamide gel electrophoresis and visualized by silver staining. A denatured pBR322 DNA/Mspl molecular weight marker (Tiangen Biotechnology (Beijing) Co. Ltd., China) was used as a size standard to identify alleles.

\section{Statistical analysis}

Allelic frequencies, genotype frequencies, Hardy-Weinberg equilibrium, and observed $\left(H_{\mathrm{O}}\right)$ and expected $\left(H_{\mathrm{E}}\right)$ heterozygosities were statistically analyzed using the POPGENE software (Version 1.31; University of Alberta, Alberta, Canada). Polymorphism information content (PIC) was determined according to the formula:

$$
P I C=1-\left(\sum_{i=1}^{n} q_{i}^{2}\right)-\left(\sum_{i=1}^{n-1} \sum_{j=i+1}^{n} 2 q_{i}^{2} q_{j}^{2}\right)
$$

where $\mathrm{q}_{i}$ and $\mathrm{q}_{j}$ are the frequencies of the ith and jth alleles at one locus; $n$ is the number of alleles at one locus. Associations between genotypes and growth traits were evaluated using the chisquare test. Results were considered to be statistically significant if two-way $P$ values were less than 0.05. Statistical analyses were carried out using the SPSS software (Version 19.0; SPSS Inc., Chicago, IL, USA).

\section{RESULTS}

A total of 120 SSR markers were initially screened in the 25 largest and 25 smallest individuals from 200 samples based on total weight and length for marker association analysis in an isolated population. Eighteen of these loci were polymorphic in S. chuatsi and were selected for further random population tests (Table 1).

A random population was amplified by using these 18 microsatellite loci (Table 2), and 70 alleles were detected in S. chuatsi. The number of alleles per locus $\left(N_{\mathrm{A}}\right)$ ranged from 2 to 6 , with an average of 3.61 alleles per locus. The effective number of alleles per locus $\left(N_{E}\right)$ ranged from 1.74 to 4.83 , with an average of 2.87 alleles per locus. $H_{O}$ and $H_{E}$ ranged from 0.44 to 1.00 (average of 0.68 ) and from 0.35 to 0.78 (average of 0.59 ), respectively. PIC ranged from 0.31 to 0.72 (average of 0.50 ).

In examining the associations between microsatellite loci and growth traits (body weight, body length, body height) (Table 3), microsatellite loci of $A P$ 37-16 were significantly associated with weight, length, and height $(P<0.01)$, while $A P$ 37-06, $A P$ 37-11, $A P$ 37-48 and $A P 38-32$ were significantly associated with length and height $(P<0.05$ or $P<0.01)$ and $A P 39-05$ significantly associated with weight and body $(P<0.05)$. AP 37-40 was only significantly associated with length $(P<0.05)$, and $A P 38-28$ only significantly associated weight $(P<0.05)$.

The eight microsatellites that showed significant differences $(P<0.05)$ were used to analyze the associations between their genotypes and growth traits (Table 4). The results showed that five genotypes were discovered at $A P 37-16$, and growth traits of genotype $A B$ were significantly greater than those of other genotypes $(P<0.01)$. For $A P 37-06$, length and height of genotype $A B$ were significantly greater compared to genotypes $B B$ and $A C(P<0.05)$. For $A P 37-11$, length and height of genotype $A A$ were significantly greater compared to $A C$ and $B B(P<0.01)$. For $A P 37$ 40 , length of $A B$ was significantly greater than that of $A C$ and $A B(P<0.05)$. For $A P 37-48$, length 
Table 1. Primer sequences and characteristics of 18 polymorphic microsatellites loci of Siniperca chuatsi.

\begin{tabular}{|c|c|c|c|c|c|}
\hline Locus & Primer sequence $\left(5^{\prime}-3^{\prime}\right)$ & Repeat motif & Size range (bp) & $\mathrm{Ta}\left({ }^{\circ} \mathrm{C}\right)$ & Accession No. \\
\hline AP37-02 & $\begin{array}{l}\text { CATGATACAATTTCCCAGC } \\
\text { CACACTAACTATGCAGGTCAC }\end{array}$ & $(\text { TTAG })_{7}$ & 211-309 & 58.0 & JX503494 \\
\hline AP37-06 & $\begin{array}{l}\text { TATCTGAAGACGGTGGGAA } \\
\text { TCTGGATGAGTTGGATGGT }\end{array}$ & $(\text { ATGCC })_{6}$ & $199-247$ & 58.0 & JX503490 \\
\hline AP37-10 & $\begin{array}{l}\text { GTGAGGCAAAGTGGCTATT } \\
\text { TTACAACTAGGACCCTTTAGACC }\end{array}$ & $(\mathrm{CT})_{15}$ & $222-277$ & 58.0 & JX503486 \\
\hline AP37-11 & $\begin{array}{l}\text { TCAGGAGGAGACAAGGGACA } \\
\text { TGAGATGTTCTGTGACGCATTA }\end{array}$ & $(\text { ATCC })_{6}$ & $202-284$ & 57.0 & JX503485 \\
\hline AP37-16 & $\begin{array}{l}\text { GGAAGCACCTTGTCGTGTA } \\
\text { GACTTTCCACTCCTTCTCCA }\end{array}$ & $(T C G)_{11}$ & $165-211$ & 57.5 & JX503480 \\
\hline AP $37-40$ & $\begin{array}{l}\text { GTAGTCAGGGCTCAGTTCAG } \\
\text { AGCCTACGAAGAGAGACAGATA }\end{array}$ & $(\mathrm{CCGATG})_{5}$ & $157-192$ & 57.5 & JX503456 \\
\hline AP37-48 & $\begin{array}{l}\text { TACAGAATCAGGAAGTGGCT } \\
\text { CTCCTGTTGCTGTGTCAAA }\end{array}$ & $(\mathrm{ACT})_{15}$ & $273-302$ & 59.0 & JX503448 \\
\hline AP38-05 & $\begin{array}{l}\text { ACAGGCCACTGTGGAAATG } \\
\text { TCAAGCACTTGATGATGTACAAT }\end{array}$ & $(\mathrm{CAG})_{9}$ & $204-231$ & 53.0 & JX503440 \\
\hline AP38-06 & $\begin{array}{l}\text { AAGCCTTGCAGTGACATAT } \\
\text { TTTGGCTTGATTGATGGTG }\end{array}$ & $(C A)_{10}$ & $247-306$ & 54.0 & JX503439 \\
\hline AP38-31 & $\begin{array}{l}\text { GCGCTTGCATGTGAGGAC } \\
\text { GTCAGACTGGAGCTGGATGTG }\end{array}$ & $(\mathrm{AC})_{18}$ & $270-320$ & 55.0 & JX503419 \\
\hline AP38-19 & $\begin{array}{l}\text { CACATATTAACAAGTCAGCGTGAG } \\
\text { ATGGCTTTGAGTTCTGAGACGA }\end{array}$ & $(\text { AATA })_{5}$ & $210-270$ & 56.0 & JX503426 \\
\hline AP38-25 & $\begin{array}{l}\text { GCAGCAGGGCAACAACCA } \\
\text { ACACGGGAACCAGGCAGA }\end{array}$ & $(\mathrm{GT})_{23}$ & $205-236$ & 55.0 & JX503422 \\
\hline AP38-32 & $\begin{array}{l}\text { CGAAGGCAAGAAGCAAGG } \\
\text { TGCCCTCAGGAAGGAATCTAC }\end{array}$ & $(\mathrm{ACC})_{7}$ & $156-231$ & 59.0 & JX503418 \\
\hline AP38-28 & $\begin{array}{l}\text { AACTGTTGGTGGTGATGAGGG } \\
\text { GATCGTGTTGGAAAGAATGTCG }\end{array}$ & $(T G A)_{8}$ & $160-220$ & 57.0 & $J X 503420$ \\
\hline AP38-39 & $\begin{array}{l}\text { CCCGCCCTTCTTTCTTTAGC } \\
\text { CCACAGTGACGTATAAATATTCAGC }\end{array}$ & $(\mathrm{CCT})_{10}$ & $142-157$ & 55.0 & JX503411 \\
\hline AP39-02 & $\begin{array}{l}\text { AGGCCAGAGCTGCTACCAAG } \\
\text { TCAAAGGGGTGATGGAGAAA }\end{array}$ & $(\mathrm{CA})_{20}$ & $257-279$ & 57.0 & JX503401 \\
\hline AP39-03 & $\begin{array}{l}\text { TTGGTTTGCTGCTTTCCCTT } \\
\text { CACGGCGACATCCAATCACT }\end{array}$ & $(\mathrm{AC})_{22}$ & $128-165$ & 57.0 & JX503400 \\
\hline AP39-05 & $\begin{array}{l}\text { CTGACAGGCAGAAGGTAGCA } \\
\text { ATTTAGCAGAGCTTTGACCC }\end{array}$ & $(\mathrm{CTG})_{7}$ & $180-280$ & 57.0 & JX503398 \\
\hline
\end{tabular}

Table 2. Genetic diversity in panmictic population of Siniperca chuatsi.

\begin{tabular}{|c|c|c|c|c|c|}
\hline Locus & $N_{\mathrm{A}}$ & $N_{\mathrm{E}}$ & $H_{0}$ & $H_{\mathrm{E}}$ & PIC \\
\hline AP37-02 & 5 & 4.8272 & 0.7656 & 0.5548 & 0.5351 \\
\hline AP37-06 & 3 & 2.8056 & 0.7998 & 0.6483 & 0.5697 \\
\hline AP37-10 & 3 & 1.7388 & 0.5345 & 0.4694 & 0.4199 \\
\hline AP37-11 & 3 & 1.946 & 0.5432 & 0.4967 & 0.4039 \\
\hline AP37-16 & 2 & 1.9429 & 0.8219 & 0.7897 & 0.5687 \\
\hline AP37-40 & 3 & 2.8381 & 0.6719 & 0.6529 & 0.5727 \\
\hline AP37-48 & 3 & 2.9554 & 1 & 0.6667 & 0.5889 \\
\hline AP38-05 & 3 & 2.5173 & 0.5045 & 0.6055 & 0.5192 \\
\hline AP38-06 & 6 & 4.0443 & 0.4362 & 0.3561 & 0.3145 \\
\hline AP38-31 & 6 & 3.7146 & 0.6864 & 0.6487 & 0.4169 \\
\hline AP38-19 & 3 & 1.9788 & 0.6577 & 0.4969 & 0.4438 \\
\hline AP38-25 & 5 & 3.5596 & 0.5329 & 0.5106 & 0.4842 \\
\hline AP38-32 & 3 & 2.4943 & 0.6435 & 0.6038 & 0.5138 \\
\hline AP38-28 & 3 & 2.5135 & 0.5634 & 0.6069 & 0.5186 \\
\hline AP38-39 & 5 & 3.7138 & 0.7321 & 0.7498 & 0.7235 \\
\hline AP39-02 & 4 & 3.7662 & 0.7712 & 0.6289 & 0.5449 \\
\hline AP39-03 & 2 & 1.7841 & 0.5942 & 0.4427 & 0.3429 \\
\hline AP39-05 & 3 & 2.6602 & 1 & 0.6298 & 0.5532 \\
\hline
\end{tabular}


Table 3. Associations between 18 microsatellite loci and body weight, body length, and body height of Siniperca chuatsi.

\begin{tabular}{lccc}
\hline Locus & Body weight & Body length & Body height \\
\hline AP37-02 & 0.181 & 0.868 & 0.326 \\
AP37-06 & 0.222 & $0.004^{* *}$ & $0.018^{*}$ \\
AP37-10 & 0.328 & 0.174 & 0.384 \\
AP37-11 & 0.073 & $0.002^{* *}$ & $0.001^{* *}$ \\
AP37-16 & $0.001^{* *}$ & $0.000^{* *}$ & $0.000^{* *}$ \\
AP37-40 & 0.085 & $0.014^{*}$ & 0.07 \\
AP37-48 & 0.096 & $0.032^{*}$ & $0.008^{* *}$ \\
AP38-05 & 0.366 & 0.123 & 0.254 \\
AP38-06 & 0.068 & 0.096 & 0.222 \\
AP38-31 & 0.318 & 0.02 & 0.064 \\
AP38-19 & 0.703 & 0.773 & 0.847 \\
AP38-25 & 0.569 & 0.069 & 0.071 \\
AP38-32 & 0.476 & $0.002^{* *}$ & $0.005^{* *}$ \\
AP38-28 & $0.031^{*}$ & 0.217 & 0.683 \\
AP38-39 & 0.318 & 0.256 & 0.098 \\
AP39-02 & 0.195 & 0.064 & 0.061 \\
AP39-03 & 0.318 & 0.203 & 0.064 \\
AP39-05 & $0.046^{*}$ & $0.017^{*}$ & 0.107 \\
\hline
\end{tabular}

*Significantly correlated with markers $(P<0.05) .{ }^{* *}$ Significantly correlated with markers $(P<0.01)$.

Table 4. Multiple comparisons of body weight, body length, and body height in 8 microsatellite loci.

\begin{tabular}{|c|c|c|c|c|c|}
\hline Locus & Genotype $^{*}$ & $\mathrm{~N}$ & Body weight (g) & Body length $(\mathrm{cm})$ & Body height $(\mathrm{cm})$ \\
\hline \multirow[t]{3}{*}{ AP37-06 } & $A B$ & 18 & $663.04 \pm 22.83$ & $30.20 \pm 0.50^{A}$ & $11.39 \pm 0.21^{a}$ \\
\hline & $B C$ & 12 & $651.94 \pm 22.88$ & $28.93 \pm 0.34^{\mathrm{B}}$ & $10.96 \pm 0.14^{\mathrm{ab}}$ \\
\hline & $A A$ & 12 & $610.40 \pm 19.57$ & $29.15 \pm 0.35^{\mathrm{AB}}$ & $10.88 \pm 0.12^{\mathrm{ab}}$ \\
\hline \multirow{3}{*}{ AP37-11 } & BB & 9 & $606.32 \pm 25.51$ & $28.19 \pm 0.35^{\mathrm{B}}$ & $10.84 \pm 0.16^{b}$ \\
\hline & $A C$ & 19 & $604.59 \pm 24.04$ & $28.40 \pm 0.28^{B}$ & $10.70 \pm 0.11^{\mathrm{b}}$ \\
\hline & AA & 26 & $658.38 \pm 16.03^{a}$ & $29.93 \pm 0.32^{\mathrm{A}}$ & $11.33 \pm 0.13^{A}$ \\
\hline \multirow[t]{5}{*}{ AP37-16 } & $A B$ & 32 & $634.34 \pm 17.37^{\mathrm{ab}}$ & $28.69 \pm 0.25^{\mathrm{AB}}$ & $10.83 \pm 0.09^{A B}$ \\
\hline & $A C$ & 6 & $579.08 \pm 24.65^{\mathrm{ab}}$ & $28.45 \pm 0.50^{\mathrm{B}}$ & $10.69 \pm 0.15^{\mathrm{B}}$ \\
\hline & BB & 6 & $572.62 \pm 28.14^{b}$ & $27.79 \pm 0.61^{\mathrm{B}}$ & $10.39 \pm 0.24^{\mathrm{B}}$ \\
\hline & AA & 28 & $678.92 \pm 14.56^{A}$ & $30.08 \pm 0.30^{A}$ & $11.32 \pm 0.13^{A}$ \\
\hline & BB & 16 & $612.57 \pm 26.50^{\mathrm{B}}$ & $28.19 \pm 0.39^{\mathrm{B}}$ & $10.56 \pm 0.15^{\mathrm{B}}$ \\
\hline \multirow[t]{3}{*}{ AP $37-40$} & $A B$ & 26 & $596.78 \pm 14.45^{\mathrm{B}}$ & $28.48 \pm 0.21^{\mathrm{B}}$ & $10.84 \pm 0.08^{B}$ \\
\hline & BB & 15 & $664.59 \pm 18.03^{b}$ & $29.29 \pm 0.25^{\mathrm{ab}}$ & $11.08 \pm 0.11^{\mathrm{ab}}$ \\
\hline & $A B$ & 16 & $648.71 \pm 25.22^{b}$ & $30.11 \pm 0.59^{b}$ & $11.31 \pm 0.24^{\mathrm{b}}$ \\
\hline \multirow[t]{7}{*}{ AP37-48 } & $A A$ & 8 & $637.67 \pm 29.71^{\mathrm{ab}}$ & $28.89 \pm 0.47^{\mathrm{ab}}$ & $10.70 \pm 0.16^{a}$ \\
\hline & $A C$ & 21 & $613.62 \pm 20.28^{\mathrm{ab}}$ & $28.56 \pm 0.29^{a}$ & $10.87 \pm 0.13^{\mathrm{ab}}$ \\
\hline & $\mathrm{BC}$ & 10 & $569.14 \pm 26.06^{a}$ & $28.18 \pm 0.30^{a}$ & $10.69 \pm 0.12^{\mathrm{a}}$ \\
\hline & $A B$ & 12 & $662.89 \pm 16.33^{b}$ & $29.19 \pm 0.32^{\mathrm{ab}}$ & $10.90 \pm 0.14^{\mathrm{AB}}$ \\
\hline & BB & 7 & $655.03 \pm 34.33^{\mathrm{ab}}$ & $29.87 \pm 0.95^{b}$ & $11.48 \pm 0.31^{c}$ \\
\hline & $A C$ & 18 & $646.38 \pm 23.61^{\mathrm{ab}}$ & $29.86 \pm 0.41^{\mathrm{b}}$ & $11.26 \pm 0.15^{\mathrm{BC}}$ \\
\hline & $\mathrm{CC}$ & 7 & $640.61 \pm 47.38^{\mathrm{ab}}$ & $28.17 \pm 0.44^{a}$ & $10.43 \pm 0.20^{\mathrm{A}}$ \\
\hline \multirow[t]{6}{*}{ AP38-28 } & $A A$ & 12 & $615.81 \pm 24.84^{\mathrm{ab}}$ & $28.51 \pm 0.25^{\mathrm{ab}}$ & $10.79 \pm 0.11^{\mathrm{AB}}$ \\
\hline & $\mathrm{BC}$ & 14 & $569.88 \pm 18.72^{\mathrm{a}}$ & $28.41 \pm 0.43^{a b}$ & $10.81 \pm 0.19^{A B}$ \\
\hline & $\mathrm{CC}$ & 4 & $657.58 \pm 88.28^{a}$ & $26.95 \pm 0.13^{\mathrm{b}}$ & $10.31 \pm 0.12^{\mathrm{b}}$ \\
\hline & AA & 15 & $653.85 \pm 26.52^{a}$ & $29.80 \pm 0.58^{a}$ & $11.18 \pm 0.23^{a}$ \\
\hline & BB & 16 & $623.88 \pm 20.70^{\mathrm{ab}}$ & $29.04 \pm 0.26^{\mathrm{a}}$ & $10.99 \pm 0.13^{a}$ \\
\hline & $A B$ & 25 & $621.81 \pm 16.97^{\mathrm{ab}}$ & $29.10 \pm 0.31^{\mathrm{a}}$ & $10.93 \pm 0.12^{\mathrm{a}}$ \\
\hline \multirow[t]{6}{*}{ AP38-32 } & $A C$ & 10 & $606.17 \pm 19.55^{b}$ & $28.71 \pm 0.35^{a}$ & $10.97 \pm 0.16^{a}$ \\
\hline & AA & 13 & $670.10 \pm 19.68$ & $30.27 \pm 0.50^{A}$ & $11.42 \pm 0.20^{A}$ \\
\hline & $A B$ & 28 & $625.26 \pm 17.72$ & $29.10 \pm 0.29^{A B}$ & $10.95 \pm 0.12^{\mathrm{AB}}$ \\
\hline & $\mathrm{BC}$ & 8 & $621.75 \pm 44.86$ & $27.39 \pm 0.44^{c}$ & $10.36 \pm 0.17^{c}$ \\
\hline & BB & 12 & $613.25 \pm 19.44$ & $28.85 \pm 0.34^{\mathrm{B}}$ & $10.83 \pm 0.13^{\mathrm{BC}}$ \\
\hline & $A C$ & 9 & $608.24 \pm 33.51$ & $28.92 \pm 0.42^{\mathrm{B}}$ & $11.09 \pm 0.20^{\mathrm{AB}}$ \\
\hline \multirow[t]{3}{*}{ AP39-05 } & $A C$ & 19 & $656.58 \pm 19.37^{a}$ & $28.96 \pm 0.29^{\mathrm{ab}}$ & $10.85 \pm 0.13^{\mathrm{ab}}$ \\
\hline & AA & 13 & $639.57 \pm 23.33^{b}$ & $29.40 \pm 0.42^{\mathrm{a}}$ & $11.05 \pm 0.16^{\mathrm{ab}}$ \\
\hline & $A B$ & 25 & $636.39 \pm 19.77^{b}$ & $29.56 \pm 0.39^{\mathrm{a}}$ & $11.17 \pm 0.16^{\mathrm{a}}$ \\
\hline
\end{tabular}

Data labeled with different superscript letters in the same column by individual locus mean significant difference. Different lowercase letters indicate significant differences $(P<0.05)$; different uppercase letters indicate significant differences $(P<0.01)$. Each genotype was considered when individual numbers were more than 4 . 
of $B B$ and $A C$ was significantly greater compared to $C C(P<0.05)$, height of $B B$ was significantly greater than that of $C C(P<0.01)$. For $A P 38-28$, weight of genotypes $A A$ and $C C$ was significantly greater than that of $A C(P<0.05)$. For $A P 38-32$, length and height of $A A$ were significantly greater compared to $B C(P<0.01)$. Therefore, $B C$ showed a negative correlation with length and height. For $A P$ 39-05, weight of $A C$ was significantly greater compared to $B C(P<0.05)$, while length of $A A$ and $A B$ was significantly greater compared to $B C(P<0.05)$.

\section{DISSCUSSION}

For aquatic animals, molecular markers are not only used for genetic monitoring in selective breeding lines (Hao et al., 2010; Yu et al., 2011) but also association analysis of target traits (Kang et al., 2002). Currently, there are two methods for using molecular markers: one is marker association analysis in a randomly selected population (Cnaani et al., 2003), and the other is marker association analysis in an isolated population (Gross and Nilsson, 1999). In this study, these two methods were used together. First, polymorphic analyses of these microsatellite loci were analyzed between the maximal weight group and minimal weight group. Second, these polymorphic markers were used for genotyping and association analysis in a random group. As a result, 18 microsatellite loci were screened between the maximal weight group and minimal weight group, and 8 loci showed significant differences in subsequent association analysis with random population testing and growth traits. The results indicated that screening markers in extreme groups could improve the efficiency of screening.

Many authors have reported that the different genotypes of microsatellite loci are positively correlated with growth traits (Fan et al., 2009; Liu et al., 2012). In this study, the results showed that microsatellite loci of $A P$ 37-16 were significantly correlated with body weight, length and height of S. chuatsi, while AP 37-06, AP 37-11, AP 37-48 and AP 38-32 were significantly associated with length and height. $A P$ 39-05 was significantly associated with weight and length $(P<0.05), A P$ $37-40$ was only significantly associated with length $(P<0.05)$, and $A P 38-28$ was only significantly associated with weight $(P<0.05)$. The finding that these loci were significantly correlated with economic traits could be useful for marker-assisted selection in breeding programs of this important aquatic species.

Among the eight loci showing significant correlations in the S. chuatsi population, eight genotypes of six loci were positively correlated with growth traits (body weight, length, and height). Genotypes $A B$ for $A P$ 37-06, AA for $A P$ 37-11, AA for $A P$ 37-16, BB and AC for $A P$ 3748, $A A$ for $A P$ 38-32, and $A C$ and $A A$ for $A P$ 39-05 exhibited significantly larger traits compare with other genotypes of the same marker. These significantly correlated loci carry an important function in evolution because they control the viability of individuals bearing different genotypes of the locus (Xu, 2008). Therefore, these kinds of genotypes could indirectly help select growth traits for $S$. chuatsi.

Heterozygosity is one of the indicators of the degree of genetic variation (Bin et al., 1999). In this study, average $H_{\mathrm{O}}$ and $H_{\mathrm{E}}$ were 0.68 and 0.59 , respectively, showing a population with a high genetic diversity. $P I C$ is the change of function allele frequency and the alleles number, and it is also a good indicator of genetic information capacity of a genetic marker (Zhu et al., 2008). According to Botstein et al. (1980), PIC is an indicator of the degree of genetic variation. In the eighteen loci of this study, eleven loci showed high polymorphism (PIC > 0.5), and seven loci medium polymorphism $(0.25<$ PIC < 0.5). The average PIC value for the 18 microsatellite loci detected in S. chuatsi was 
0.50, showing that they were highly polymorphic loci. These novel markers will facilitate further studies on genetic diversity evaluation, conservation genetics, construction of high-density linkage map and molecular marker-assisted breeding of $S$. chuatsi and its related species.

In conclusion, 120 SSR markers were initially screened in the 25 largest and 25 smallest individuals from 200 samples on the basis of total weight and length for marker association analysis in an isolated population. Eighteen of these loci were polymorphic in S. chuatsi and were selected for further random population tests. We found that eight genotypes of six loci were positively correlated with growth traits (body weight, length and height) in the S. chuatsi population. Average $H_{0}$ and $H_{E}$ were 0.68 and 0.59 , respectively, and the average PIC value was 0.50 , indicating a population with high genetic diversity. In addition, these loci were significantly correlated with growth traits, indicating that they could be useful for marker-assisted selection in breeding programs of this important aquatic species and its related species.

\section{Conflicts of Interest}

The authors declare no conflict of interest.

\section{ACKNOWLEDGMENTS}

Research supported by the National Natural Science Foundation of China (\#31272641 and \#31172420), the National Basic Research Program of China (\#2014CB138601), the Key Projects in the National Science \& Technology Pillar Program during the Twelfth Five-year Plan Period (\#2012BAD25B04), and the Fundamental Research Funds for the Central Universities (\#2011PY030, \#2013PY072).

\section{REFERENCES}

Botstein D, White RL, Skolnick M and Davis RW (1980). Construction of genetic linkage map in man using restriction fragment length polymorphisms. Am. J. Human Genet. 32: 314 -331.

Cnaani A, Hallerman EM, Ron M, Weller JI, et al. (2003). Detection of a chromosomal region with two quantitative trait loci, affecting cold tolerance and fish size, in an $\mathrm{F}_{2}$ tilapia hybrid. Aquaculture 223: 117-128.

Fan B, Li K, Peng ZZ, Chen Y, et al. (1999). Genetic variation of 27 microsatellite loci in three Hubei indigenous pig breeds. Chin. Biodiv. 7: 91-96.

Fan JJ, Bai JJ, Li XH, He XP, et al. (2009). Identification of microsatellite markers associated with growth traits in largemouth bass (Micropterus salmoides L.). Hereditas 31: 515-522.

Gpta PK and Rustgi S (2004). Molecular markers from the transcribed/expressed region of the genome in higher plants. Funct. Integr. Genomics 4: 139-162.

Gross R and Nilsson J (1999). Restriction fragment length polymorphism at the growth hormone 1 gene in Atlantic salmon (Salmo salar L.) and its association with weight among the offspring of a hatchery stock. Aquaculture 173: 73-80.

Hao GT, Liu XD, Wang ZY, Cai MY, et al. (2010). Genetic structure and genetic diversity analysis of four consecutive breeding generations of large yellow croaker (Pseudosciaena crocea) using microsatellite markers. J. Fish. China 34: 500-507.

Kang JH, Lee SJ, Park SR and Ryu HY (2002). DNA polymorphism in the growth hormone gene and its association with weight in olive flounder Paralichthys olivaceus. Fish. Sci. 68: 494-498.

Liang XF (1996). Study on Mandarin fish and its culture home and abroad. Fish. Sci. Tech. Inf. 23: 13-17.

Liu J, Cui Y and Liu J (1998). Food consumption and growth of two piscivorous fishes, the mandarin fish and the Chinese snakehead. J. Fish Biol. 53: 1071-1083.

Liu L, Li J, Liu P, Zhao FZ, et al.. (2012). Correlation analysis of microsatellite DNA markers with growth related traits of swimming crab (Portunus trituberculatus). J. Fish. China 36: 1034-1041.

Mi GQ, Zhao JL, Jia YY, Deng YF, et al. (2010). Morphological and microsatellite analysis of Siniperca chautsi $q$ x Siniperca scherzeri 3 hybrid with their parents. J. Shanghai Ocean Univ. 19: 145-151. 
Saha MC, Mian MA, Eujay I, Zwonitzer JC, et al. (2004) Tall fescue EST-SSR markers with transfer ability across several grass species. Theor. Appl. Genet. 109: 783-791.

Sun BJ and Nie P (2004) Molecular cloning of the viperin gene and its promoter region from the mandarin fish Siniperca chuatsi. Vet. Immunol. Immunopathol. 101: 161-170.

Walter R and Epperson BK (2001). Geographic pattern of genetic variation in Pinus resinosa: area of greatest diversity is not the origin of postglacial populations. Mol. Ecol. 10: 103-111.

Xu SZ (2008). Quantitative trait locus mapping can benefit from segregation distortion. Genetics 180: 2201-2208.

Yang X, Yang JF, Tang ML, Peng Z, et al. (2007) Intraspecific genetic polymorphisms of Siniperca scherzeri steindacher and molecular identification with Siniperca chuatsi. Acta Hydrobiol. Sin. 31: 891-895.

Yu ZF, Yan XW, Yang F, Wang JH, et al. (2011). Genetic diversity of different generations of the Dalian population of Manila clam Ruditapes philippinarum through selective breeding. Acta Ecol. Sin. 31: 4199-4206.

Zhu GQ, Wang LX, Sun RP, Liang ZY, et al. (2008). Litter size effects of six microsatellite markers in Xinong Saanen dairy goat. J. China Agric. Univ. 3: 012 